\title{
Characterizations of the thermal decomposition of nano-magnesium hydroxide by positron annihilation lifetime spectroscopy
}

Wei Yang, Zhejie Zhu, Jianjian Shi, Bin Zhao, Zhiquan. Chen, Yichu Wu*

School of Physics and Technology, Hubei Nuclear Solid Physics Key Laboratory, Wuhan University, Wuhan 430072, China

* Corresponding author. Tel.: +8627 68752370, Fax: +862768753880.

E-mail address: ycwu@whu.edu.cn (Yichu Wu)

\begin{abstract}
The thermal decomposition behavior of magnesium hydroxide $\left(\mathrm{Mg}(\mathrm{OH})_{2}\right)$ nanopowders was investigated by positron annihilation lifetime spectroscopy (PALS), X-ray diffraction (XRD), thermogravimetric and differential scanning calorimetry (TG-DSC) analysis, high-resolution transmission electron microscopy (HRTEM) and scanning electron microscopy (SEM). It was indicated that the microstructural changes started from $300{ }^{\circ} \mathrm{C}$ were earlier than the phase transformation from hexagonal $\mathrm{Mg}\left(\mathrm{OH}_{2}\right.$ nanopowders to face-centered cubic $\mathrm{MgO}$ occurred at about 380 ${ }^{\circ} \mathrm{C}$ during decomposition process. The variation of positron annihilation parameters revealed the production of new vacancy defects and the aggregation of vacancy clusters in grain boundary areas and microvoids between particles due to the removal of $\mathrm{H}_{2} \mathrm{O}$ and rearrangement of interface atoms. A positron trapping model was proposed to help further understand the changes of microstructure and interfacial defects during $\mathrm{Mg}(\mathrm{OH})_{2}$ thermal decomposition.
\end{abstract}

Keywords: Positron annihilation; structural defects; decomposition; magnesium hydroxide 


\section{Introduction}

Nano-magnesium hydroxide $\left(\mathrm{Mg}(\mathrm{OH})_{2}\right)$ is widely used in many industrial fields, such as flame-retardant [1], water treatment [2], biomedicine [3], and as the most important magnesium oxide $(\mathrm{MgO})$ precursor $[4,5]$. As nano- $\mathrm{MgO}$ has high efficiency in antibacterial agents [6], catalysts [7], adsorbents [8], and optoelectronic materials [9], many different synthetic methods were developed to obtain $\mathrm{MgO}$ nanoparticles, such as microemulsion-based oil/water interface precipitation [10], hydrothermal reaction [11] and chemical precipitation [12]. Calcining or drying kinds of modified $\mathrm{Mg}(\mathrm{OH})_{2}$ precursor is an easily accessible and cost-effective method to obtain $\mathrm{MgO}$ [13]. Pilarska et al. synthesized a plate morphology of poly(ethylene glycols)-modified $\mathrm{Mg}(\mathrm{OH})_{2}$ particles and the calcinate $\mathrm{MgO}$ could be used as insulating materials because of its permittivity $\varepsilon$ ' independent of frequency [5]. The resulting $\mathrm{MgO}$ properties strongly depend on the shape, agglomeration state, preparation process and decomposition process of $\mathrm{Mg}(\mathrm{OH})_{2}$ [4, 14]. However, in recent years, few work paid attention to the thermal decomposition behaviour of nano- $\mathrm{Mg}(\mathrm{OH})_{2}$.

The decomposition of $\mathrm{Mg}(\mathrm{OH})_{2}$ is generally viewed as a two-phase process occurred in the temperature range of $280 \sim 450{ }^{\circ} \mathrm{C}$. The resulting $\mathrm{MgO}$ structure from $\mathrm{Mg}(\mathrm{OH})_{2}$ decomposition maintains a distinct crystallographic relationship with original $\mathrm{Mg}(\mathrm{OH})_{2}$, which is $(0001) \mathrm{Mg}(\mathrm{OH})_{2} \|(111) \mathrm{MgO}$ and [1120] $\mathrm{Mg}(\mathrm{OH})_{2} \|[10$ 1] $\mathrm{MgO}$ [15]. Several kinds of decomposition mechanism have been proposed from kinetics, energetics, morphology and crystallography. A phase-boundary controlled mechanism was that the decomposition reaction proceeded by the advance of an interface two-dimensional reaction from the perimeter to the center of basal plane of hydroxide crystal [16]. In a homogenous mechanism, the migration of $\mathrm{H}_{2} \mathrm{O}$ molecules from the planes to the surface was thought to control the structure change of $\operatorname{Mg}(\mathrm{OH})_{2}$ to $\mathrm{MgO}$ [17]. The nucleation and development of $\mathrm{MgO}$ in two directions of interface was considered more acceptable because it could successfully describe the kinetics of $\mathrm{Mg}(\mathrm{OH})_{2}$ decomposition [18]. McKelvy et al. [19] also discovered that the lamellar nucleation and growth processes governed dehydroxylation of lamellar $\operatorname{Mg}(\mathrm{OH})_{2}$. However, the atomic-scale nature (defects) of the decomposition process is lack of attention. The defects information in atomic-scale are important to the properties of $\mathrm{MgO}$, e.g. the new introduced defects in $\mathrm{MgO}$ produced by $\mathrm{Mg}(\mathrm{OH})_{2}$ decomposition 
contributed to the luminescence of $\mathrm{MgO}$ [4], and the interfacial defects in $\mathrm{MgO}$ nanocrystals were related to its ferromagnetism [20].

The principle of operation of positron annihilation lifetime spectroscopy (PALS) is to measure the spectrum of time intervals between start signals, generated by detecting prompt gamma rays following the emission of positrons, and stop signals from one of the annihilation gamma photons. A positron is the antiparticle of an electron, and it can get trapped by defects without positive charge, i.e. by vacancies or other open volume defects. Positrons can also get trapped by negative ions or by solute aggregates with higher positron affinity than the host atoms. Thus PALS is a unique and valuable technique to characterize the vacancy-type defects and open volume defects in solid based on the detection of $\gamma$-radiation [21, 22], which convey information of the lifetime of positrons. In addition, the correct identification of defects with PALS requires the knowledge of accurate positron lifetimes for the various kinds of defects, which can be provided by first-principles calculations. In most studies, positron lifetimes are calculated using a simple practical method proposed by Puska and Nieminen [23, 24] based on density function theory (DFT), where the electron and positron densities are determined without imposing self-consistency.

PALS method has been successfully used to study advanced semiconductor [25, 26], nano-ceramic [27] and nano-porous material [28]. In hydrogenation-modified $\mathrm{TiO}_{2}$, a huge number of oxygen vacancies introduction were found by PALS measurements, which retarded the charge recombination and improved the photocatalytic activity of $\mathrm{TiO}_{2}$ [26]. In report of Dutta et al. [29], PALS results revealed that high temperature annealed $\mathrm{ZnO}$ semiconductor had a better crystallinity (or lower defect concentration). But no reports about the thermal decomposition of nanomaterials by PALS were found. Therefore, in this work, the thermal decomposition of $\operatorname{Mg}(\mathrm{OH})_{2}$ nanopowders with different temperatures annealing were investigated by using PALS technique, X-ray diffraction (XRD), thermogravimetric and differential scanning calorimetry (TG-DSC) analysis, high resolution transmission electron microscopy (HRTEM), and scanning electron microscopy (SEM). The changes of microstructure and interfacial defects before and after decomposition from $\mathrm{Mg}(\mathrm{OH})_{2}$ to $\mathrm{MgO}$ were discussed.

\section{Experimental}

\subsection{Sample preparation}


Nano-sized $\mathrm{Mg}(\mathrm{OH})_{2}$ powders ( $30 \mathrm{~nm}$ particle size ) synthesized by chemical coprecipitation with a purity of $99.9 \%$ were purchased from Beijing DK Nano Technology Co. LTD, China. After being milled in agate mortar, nanopowders were pressed into tablet under a static pressure of about $10 \mathrm{MP}$ for $4 \mathrm{~min}$. The tablet had a diameter about $10 \mathrm{~mm}$ and a thickness about $2 \mathrm{~mm}$. The isochronally annealing experiments were carried on these samples at different temperatures in the range of $100 \sim 520{ }^{\circ} \mathrm{C}$ in air for $2 \mathrm{~h}$. The heating rate was about $5{ }^{\circ} \mathrm{C} / \mathrm{min}$.

\subsection{Characterization}

The PALS measurements were performed on annealed samples immediately after cool down in air. In the measurements, PALS is a conventional fast-fast coincidence system with a time resolution of about 280 ps. The isotope positron source was ${ }^{22} \mathrm{Na}$ with intensity about $7.4 \times 10^{5} \mathrm{~Bq}$, which was sealed between two Kapton films. During the measurement, the positron source and two identical samples were set as a sandwich structure placed between two gamma ray detectors. Each positron annihilation spectrum was collected with a total count of $1 \times 10^{6}$ and analyzed by LT Version 9 program [30] to decompose several lifetime components. Before sample measurements, the spectrum of pure Si single crystal was measured to determine the components of positron annihilation in the source and Kapton films.

XRD (Bruker D8 Advance, $\mathrm{Cu} \mathrm{K \alpha}$ ) was performed on samples annealed at different temperatures. The thermal decomposition behavior of the as-received $\mathrm{Mg}(\mathrm{OH})_{2}$ nanopowders were studied by thermogravimetric (TG) and differential scanning calorimeter (DSC) analysis (NETZSCH STA 449C) in a temperature range of $20 \sim 800{ }^{\circ} \mathrm{C}$ with heating rate of $5{ }^{\circ} \mathrm{C} / \mathrm{min}$ under $\mathrm{N}_{2}$ flow. The micromorphology of samples before and after annealing was characterized using HRTEM (JEM-2100, JEOL, Japan) and SEM (Sirion 200, FEI, Netherlands).

\subsection{Theoretical calculation}

The theoretical positron lifetimes of perfect $\mathrm{Mg}(\mathrm{OH})_{2}$ and $\mathrm{MgO}$ lattices with and without vacancy defect were calculated, by using atomic superposition (ATSUP) method based on density function theory (DFT) [24]. In calculation models, the space group of $\mathrm{Mg}(\mathrm{OH})_{2}$ and $\mathrm{MgO}$ are $D_{3 d^{3}}-P \overline{3} m 1$ and $F m-3 m$, respectively. The experimental lattice parameters of brucite structure $\mathrm{Mg}(\mathrm{OH})_{2}$ and rock-salt structure $\mathrm{MgO}$ were $a=b=3.147 \AA, c=4.768 \AA$, and $a=b=c=4.217 \AA$, respectively. Perfect $\mathrm{Mg}(\mathrm{OH})_{2}$ lattice was modeled by a $4 \times 4 \times 2$ supercell, which contianed a total of 160 
atoms. Perfect $\mathrm{MgO}$ lattice was modeled by a $2 \times 2 \times 2$ supercell, which cotnianed a total of 64 atoms. The vacancy-type defects of $V_{\mathrm{Mg}}, V_{\mathrm{OH}}$ and $V_{\mathrm{Mg}-\mathrm{OH}}$ in $\mathrm{Mg}(\mathrm{OH})_{2}$ lattice and $V_{\mathrm{Mg}}$ in $\mathrm{MgO}$ lattice were constructed by removing the atoms of $\mathrm{Mg}, \mathrm{OH}$, and $\mathrm{Mg}-\mathrm{OH}$ from the interior of perfect lattices, respectively.

\section{Results and discussion}

\subsection{XRD analysis}

The XRD patterns of $\mathrm{Mg}(\mathrm{OH})_{2}$ nanopowders annealed at different temperatures are shown in Fig. 1. The results show that below $400{ }^{\circ} \mathrm{C}$, the nanopowders are still hexagonal $\mathrm{Mg}(\mathrm{OH})_{2}$ and no $\mathrm{MgO}$ or other intermediate phases are observed. But above $400{ }^{\circ} \mathrm{C}$, the structure of nanopowders transforms from hexagonal $\mathrm{Mg}(\mathrm{OH})_{2}$ to face-centered cubic $\mathrm{MgO}$. The decomposition reaction

$$
\mathrm{Mg}(\mathrm{OH})_{2} \rightarrow \mathrm{MgO}+\mathrm{H}_{2} \mathrm{O}
$$

occurred at a temperature between $350{ }^{\circ} \mathrm{C}$ and $400{ }^{\circ} \mathrm{C}$. This result is consistent with a in-situ XRD measurement for $\mathrm{Mg}(\mathrm{OH})_{2}$ nano-flakes [31]. The average grain size of each sample is estimated from full width at half maximum (FWHM) of the diffraction peaks by Scherrer equation [32]. The obtained values as a function of annealing temperature are shown in Fig. 2. It can be observed that the average grain size increases slightly from the original $33 \mathrm{~nm}$ to about $40 \mathrm{~nm}$ below $350{ }^{\circ} \mathrm{C}$, then rapidly decreases to about $25 \mathrm{~nm}$ up to $400{ }^{\circ} \mathrm{C}$, and finally increases again with the annealing temperature. The slight increase before decomposition is caused by the agglomeration and growth of $\operatorname{Mg}(\mathrm{OH})_{2}$ nanoparticles under lower temperature heating due to the higher surface energy of $\mathrm{Mg}(\mathrm{OH})_{2}$ nanoparticles. The rapid decrease corresponds to the decomposition process with $\mathrm{MgO}$ product formation. The new formed $\mathrm{MgO}$ products with small size coincide with the report of Yoshida et al. [33]. The final increase could be explained as the growth of $\mathrm{MgO}$ crystals under higher temperature annealing [34]. The results obey the mechanism of $\mathrm{MgO}$ nucleation and growth during $\mathrm{Mg}(\mathrm{OH})_{2}$ decomposition.

\subsection{TG-DSC analysis}

The TG-DSC measurement was carried out to analyze the thermal decomposition behavior of the as-recieved $\mathrm{Mg}(\mathrm{OH})_{2}$ nanopowders. The TG and DSC curves are both shown in Fig. 3. A significant weight loss from $97.2 \%$ to $70.8 \%$ appears in the temperature range of $300 \sim 400{ }^{\circ} \mathrm{C}$, which corresponds to the decomposition process 
from $\mathrm{Mg}(\mathrm{OH})_{2}$ to $\mathrm{MgO}$ accompanying with $\mathrm{H}_{2} \mathrm{O}$ removal. For $\mathrm{Mg}(\mathrm{OH})_{2}$ nanoparticles, the stage of weight loss generally has a little difference varying from synthesis methods and different structure of $\operatorname{Mg}(\mathrm{OH})_{2}$ [4, 31, 35, 36]. The corresponding DSC curve only shows one obvious endothermic peak at about $380{ }^{\circ} \mathrm{C}$, which means the maximum rate of weight loss at the temperature. It indicates that the phase transformation from $\mathrm{Mg}(\mathrm{OH})_{2}$ to $\mathrm{MgO}$ occurred at about $380{ }^{\circ} \mathrm{C}$, which is consistent with the result of XRD. As we know, during thermal decomposition the endothermic is to broke the ionic bond of $\mathrm{Mg}(\mathrm{OH})_{2}$, but before decomposition the endothermic could induce agglomeration and growth of some $\mathrm{Mg}(\mathrm{OH})_{2}$ nanoparticles as reflected in Fig. 2. It has been suggested that during thermal decomposition, $\mathrm{MgO}$ structure formed in $\mathrm{Mg}(\mathrm{OH})_{2}$ parent crystals with certain orientations according to a gradual change of the diffraction patterns from $\mathrm{Mg}(\mathrm{OH})_{2}$ to $\mathrm{MgO}[16,17]$. Hence, the weight loss and grain size change during decomposition would inevitably induce a maze of microstructure in nanoparticles.

\subsection{Analysis of positron annihilation lifetime spectra}

In order to the details of microstructural change for $\mathrm{Mg}(\mathrm{OH})_{2}$ nanoparticles during thermal decomposition, we performed positron annihilation lifetime measurement on samples annealed at different temperatures. The obtained positron annihilation spectrum was the convolution of the time-dependent positron decay spectrum

$$
L(t)=\sum_{i} I_{i} \exp \left(-t / \tau_{i}\right)
$$

and the Gaussian resolution function of the spectrometer, where $\tau_{i}$ is the positron lifetime in different annihilation sates and $\mathrm{I}_{i}$ is the corresponding relative intensity. Fig. 4 illustrates the positron lifetime spectra of samples annealed at different temperatures. The spectra were analyzed by using LT Version 9 program [30]. For all the samples, three positron lifetime component $\tau_{1}, \tau_{2}$, and $\tau_{3}$ with corresponding relative intensities $I_{1}, I_{2}$ and $I_{3}$ were obtained. These parameters as a function of annealing temperature are shown in Figs. 5(a)-(f), respectively. The shortest lifetime $\tau_{1}$ has a slight increase from $199 \pm 7.8$ to $208 \pm 4.8$ ps while $\mathrm{I}_{1}$ increases evidently in 300 400 ${ }^{\circ} \mathrm{C}$. In the same temperature range, the second lifetime $\tau_{2}$ shows an evident increase from $420 \pm 18$ to $452 \pm 14$ ps, while $\mathrm{I}_{2}$ significantly decreases from $38 \%$ to $28 \%$. All the samples yielded a long lifetime $\tau_{3}$, which increases in $300 \sim 400{ }^{\circ} \mathrm{C}$, while the corresponding relative intensity $\mathrm{I}_{3}$ decreases from the values about $4.5 \%$ to about 
$1.0 \%$. The changes of positron lifetime components in $300 \sim 400{ }^{\circ} \mathrm{C}$ correspond to the average grain size decrease by XRD and obvious weight loss by TG-DSC as shown in Fig. 2 and Fig. 3. The fitted lines of lifetime components $\tau_{2}$ and $\tau_{3}$ for as-received and $400{ }^{\circ} \mathrm{C}$ annealed samples were also added in Fig.4. The $\tau_{1}$ components were not indicated as a straight line, because they have no obvious increase and close to the time resolution. The slop of the straight line is according to $\lambda=\Delta \ln L(t) / \Delta t$ strictly. The $\lambda$ represents annihilation rate, which is the reciprocal of the $\tau$.

In addition, we calculated the theoretical lifetimes of perfect $\mathrm{Mg}(\mathrm{OH})_{2}$ and $\mathrm{MgO}$ lattices with and without vacancy defect using atomic superposition (ATSUP) method based on density function theory (DFT) [24] and the calculated results are shown in Table 1. The bulk lifetime of perfect $\operatorname{Mg}(\mathrm{OH})_{2}$ is about $176 \mathrm{ps}$, while the lifetime values of monovacancy $V_{\mathrm{Mg}}$, divacancy $V_{\mathrm{OH}}$ and vacancy complexes $V_{\mathrm{Mg}-\mathrm{OH}}$ are 184 , 189 and 215 ps, respectively. Similarly, the bulk lifetime of perfect $\mathrm{MgO}$ lattice is about $123 \mathrm{ps}$, while the value of monovacancy $V_{\mathrm{Mg}}$ is $174 \mathrm{ps}$. The calculated lifetime value for perfect $\mathrm{MgO}$ without defect is similar to the reported value of 119 ps by Puska et al. [37]. The experimental values of $\tau_{1}$ are much higher than the theoretical values of bulk with monovacancy, but lower than that with vacancy complexes $V_{\mathrm{Mg}-\mathrm{OH}}$. Therefore, we suggest that much higher $\tau_{1}$ of annealing $\mathrm{Mg}(\mathrm{OH})_{2}$ nanoparticles and decomposition product $\mathrm{MgO}$ in the present case are ascribed to positrons annihilating in bulk and some vacancies, vacancy complexes or small-size defects (such as divacancies), which are mostly located in grain boundary areas.

Positron annihilation lifetime is proportion to the size of defects and the relative intensity is proportion to the density of defects [24]. The increase of $\tau_{1}$ and $I_{1}$ in 300 400 ${ }^{\circ} \mathrm{C}$ (see Figs. 5(a) and (d)) indicates that the number of vacancy defects in grain boundary areas increased significantly, while the size was almost no change. More vacancy defects were formed in product $\mathrm{MgO}$ due to the removal of $\mathrm{H}_{2} \mathrm{O}$ and crystal type change during decomposition. In early performed [38, 39], similar longlived $\tau_{2} \approx 0.4 \sim 0.6 \mathrm{~ns}$ with an intensity $\mathrm{I}_{2}=50 \%$ have been detected in alkali halides, which was explained as being attributed to major processes ( I ) annihilation from a complex compound ( $\mathrm{e}^{+}$-anion) and (II) annihilation with vacancy A-centers (crystal defects). In the present case, the second lifetime components $\tau_{2}$ of $\mathrm{Mg}(\mathrm{OH})_{2}$ and $\mathrm{MgO}$ are attributed to positrons annihilating in the intersections of several interfaces or 
some vacancy clusters in grain boundary areas. For $\mathrm{MgO}$ nanocrystals, the vacancy defects including vacancies and vacancy clusters were considered to be responsible for the ferromagnetism of crystals [40, 41]. According to the variation of $\tau_{2}$ and $\mathrm{I}_{2}$, it can be inferred that during decomposition process, those vacancy clusters in $\operatorname{Mg}(\mathrm{OH})_{2}$ grain boundary areas gradually diffused together and aggregated into larger clusters with atoms rearrangement and grain boundary migration.

In the experiment, the existence of longlived component $\tau_{3}$ with identifiable intensity confirms that positroniums could be formed in $\mathrm{Mg}(\mathrm{OH})_{2}$ nanoparticles. Generally, positronium is favorable formation in porous materials by catch one electron. Positronium has two kinds of spin states, the long-lived ortho-positronium (o-Ps, $142 \mathrm{~ns}$ ) and the short-lived para-positronium (p-Ps, $125 \mathrm{ps}$ ). In condensed matter, the lifetime of o-Ps can be greatly reduced to $1 \sim 10 \mathrm{~ns}$ by picking up a surrounding electron and then annihilating with it. The process is called pick-up annihilation with the lifetime closely related to the size of the pore. The positroniums formation and annihilation in hydroxides compounds are very similar to those in porous materials and molecular system [39]. The existence of $\tau_{3}$ and $\mathrm{I}_{3}$ indicates that the as-received $\mathrm{Mg}(\mathrm{OH})_{2}$ nanoparticles contained a small number of microvoids before annealing. The increase of $\tau_{3}$ in 300 400 ${ }^{\circ} \mathrm{C}$ demonstrates that larger size of microvoids were formed in $\mathrm{MgO}$ product by thermal decomposition. It has been known that during thermal decomposition of $\mathrm{Mg}(\mathrm{OH})_{2}$, the removal of $\mathrm{H}_{2} \mathrm{O}$ would leave a periclase structure of $\mathrm{MgO}$ with many open volume microvoids between particles and irregular intercrystallite channels (cracks). These new formed open volume microvoids and cracks with larger size probably exceeded the detected range of PALS measurement, resulting in the decrease of $\mathrm{I}_{3}$.

In Fig. 5, the variation of positron lifetimes and corresponding relative intensities all start at $300^{\circ} \mathrm{C}$. It indicates that the changes of microstructure and interfacial defects of $\mathrm{Mg}(\mathrm{OH})_{2}$ nanoparticles are earlier than the phase transformation from hexagonal $\mathrm{Mg}\left(\mathrm{OH}_{2}\right.$ nanopowders to face-centered cubic $\mathrm{MgO}$ occurred at $380{ }^{\circ} \mathrm{C}$ during decomposition process. The changes of interfacial defects in nanoparticles are hard to be characterized by HRTEM or other traditional techniques. Schaefer et al. [42] once proposed a positron annihilation model to investigate the surface and interface of nanometer-sized polycrystalline Fe specimens based on positron lifetime spectroscopy. The model clearly illustrated the location of monovacancy $\left(\tau_{1}\right)$ in interface, vacancy 
clusters $\left(\tau_{2}\right)$ at the intersections of several interfaces and larger voids $\left(\tau_{3}\right)$ at surface. Here, we suggest a possible positron trapping model for thermal decomposition of $\mathrm{Mg}(\mathrm{OH})_{2}$ nanoparticles on the basis of the model of Schaefer et al. The schematic of the model is shown in Fig. 6. For $\mathrm{Mg}(\mathrm{OH})_{2}$ nanoparticles and $\mathrm{MgO}$ product particles, positrons were trapped in the vacancies/vacancy complexes $\left(\tau_{1}\right)$ at grain boundary areas, the vacancy clusters $\left(\tau_{2}\right)$ at the intersections of several interfaces, and the larger open or closed microvoids or pores $\left(\tau_{3}\right)$ between particles, respectively. After thermal decomposition, more vacancies/vacancy complexes were formed in $\mathrm{MgO}$ products resulting in more positrons being trapped in these sites. Meanwhile, original vacancy clusters and microvoids aggregated into larger ones due to the rearrangement of atoms and the migration of grain boundaries. Positrons had a longer lifetime when annihilating in these larger-size vacancy clusters and microvoids. This model provides a further understand of the decomposition mechanism in atomic-scale and could be applied to some other tentative nanoparticles.

\subsection{Micromorphology}

Fig. 7 illustrates the TEM images of $\mathrm{Mg}(\mathrm{OH})_{2}$ nanopowders in as-received and $400{ }^{\circ} \mathrm{C}$ annealed $\operatorname{Mg}(\mathrm{OH})_{2}$ samples. The image of the as-received sample in Fig. 7(a) indicates a well crystallinity of $\mathrm{Mg}(\mathrm{OH})_{2}$ particles despite with some agglomeration. In Fig. 7(b), the annealed sample shows a porous and cracked structure due to the removal of $\mathrm{H}_{2} \mathrm{O}$ and $\mathrm{MgO}$ crystallization during decomposition. The HRTEM images of annealed sample in Fig. 8(b) acquired in the area indicated by the red small box in Fig. 8(a). The lattice fringes are separated by a distance of $0.243 \mathrm{~nm}$ which is attributed to the (111) plane of cubic phase of $\mathrm{MgO}$. The blurred crystal texture demonstrates the presence of some vacancy defects in $\mathrm{MgO}$ bulk. The internal interfaces containing vacancy complexes or small-size defects (divacancies) and vacancy clusters are located in disorientated regions between nanoparticles.

The SEM images in Fig. 9 show the micromorphology of $\mathrm{Mg}(\mathrm{OH})_{2}$ nanopowders in as-received and $350{ }^{\circ} \mathrm{C}$ and $400{ }^{\circ} \mathrm{C}$ annealed samples. The as-received $\mathrm{Mg}(\mathrm{OH})_{2}$ nanoparticles have an aggregation with no special morphology. The $\operatorname{Mg}(\mathrm{OH})_{2}$ sample annealed at $350{ }^{\circ} \mathrm{C}$ shows a "dissolution" phenomenon partially before decomposition. This evident microstructural change at $350{ }^{\circ} \mathrm{C}$ is consistent with the view of microstructural change ahead of phase transformation during $\mathrm{Mg}(\mathrm{OH})_{2}$ decomposition. For the $400{ }^{\circ} \mathrm{C}$ annealed sample, a large number of tiny crystals appear due to 
nucleation and growth of $\mathrm{MgO}$ product, which is agree with the XRD and HRTEM results.

\section{Conclusions}

PALS, XRD, TG-DSC, HRTEM and SEM were employed to investigate the thermal decomposition behavior of $\operatorname{Mg}(\mathrm{OH})_{2}$ nanopowders. The XRD and TG-DSC results demonstrate that the decomposition of $\operatorname{Mg}(\mathrm{OH})_{2}$ happened in the temperature range of $300 \sim 400{ }^{\circ} \mathrm{C}$ and the phase transformation from $\mathrm{Mg}(\mathrm{OH})_{2}$ to $\mathrm{MgO}$ occurred at $380{ }^{\circ} \mathrm{C}$. The PALS results indicate that the microstructural changes of $\mathrm{Mg}(\mathrm{OH})_{2}$ nanopowders are earlier than the phase transformation occurred at $380{ }^{\circ} \mathrm{C}$. During decomposition from $\mathrm{Mg}(\mathrm{OH})_{2}$ to $\mathrm{MgO}$, new vacancy defects were produced, and the vacancy clusters in grain boundary areas and microvoids between particles aggregated into larger size due to the removal of $\mathrm{H}_{2} \mathrm{O}$ and rearrangement of interface atoms. A positron trapping model for thermal decomposition of $\mathrm{Mg}(\mathrm{OH})_{2}$ nanopowders has been proposed to further understand the atomic-scale decomposition mechanism. The blurred crystal texture in $\mathrm{MgO}$ product observed by HRTEM shows the presence of some vacancy defects.

\section{Acknowledgements}

This work was supported by National Science Foundation of China (No. $11675123)$. 


\section{References}

[1] L. Qiu, R. Xie, P. Ding, B. Qu, Preparation and characterization of $\operatorname{Mg}(\mathrm{OH})_{2}$ nanoparticles and flame-retardant property of its nanocomposites with EVA, Compos. Struct. 62 (2003) 391-395.

[2] M. Liu, Y. Wang, L. Chen, Y. Zhang, Z. Lin, $\operatorname{Mg}(\mathrm{OH})_{2}$ supported nanoscale zero valent iron enhancing the removal of $\mathrm{Pb}$ (II) from aqueous solution, ACS Appl. Mater. Interfaces 7 (2015) 7961-7969.

[3] X. Pan, Y. Wang, Z. Chen, D. Pan, Y. Cheng, Z. Liu, Z. Lin, X. Guan, Investigation of antibacterial activity and related mechanism of a series of nano- $\mathrm{Mg}(\mathrm{OH})_{2}$, ACS Appl. Mater. Interfaces 5 (2013) 1137-1142.

[4] L. Kumari, W.Z. Li, C.H. Vannoy, R.M. Leblanc, D.Z. Wang, Synthesis, characterization and optical properties of $\mathrm{Mg}(\mathrm{OH})_{2}$ micro-/nanostructure and its conversion to $\mathrm{MgO}$, Ceram. Int. 35 (2009) 3355-3364.

[5] A. Pilarska, M. Wysokowski, E. Markiewicz, T. Jesionowski, Synthesis of magnesium hydroxide and its calcinates by a precipitation method with the use of magnesium sulfate and poly(ethylene glycols), Powder Technol. 235 (2013) 148-157.

[6] K. Krishnamoorthy, J.Y. Moon, H.B. Hyun, S.K. Cho, S.J. Kim, Mechanistic investigation on the toxicity of $\mathrm{MgO}$ nanoparticles toward cancer cells, J. Mater. Chem. 22 (2012) 24610-24617.

[7] J. Scholz, A. Walter, T. Ressler, Influence of MgO-modified SBA-15 on the structure and catalytic activity of supported vanadium oxide catalysts, J. Catal. 309 (2014) 105-114.

[8] G. Song, X. Zhu, R. Chen, Q. Liao, Y.D. Ding, L. Chen, An investigation of $\mathrm{CO}_{2}$ adsorption kinetics on porous magnesium oxide, Chem. Eng. J. 283 (2016) 175-183.

[9] S. Stankic, M. Muller, O. Diwald, M. Sterrer, E. Knozinger, J. Bernardi, Size-dependent optical properties of $\mathrm{MgO}$ nanocubes, Angew. Chem. Int. Ed. 44 (2005) 4917-4920.

[10] S. Li, B. Zhou, B. Ren, L. Xing, L. Tan, L. Dong, J. Li, Preparation of MgO nanomaterials by microemulsion-based oil/water interface precipitation, Mater. Lett. 171 (2016) 204-207.

[11] Y. Ding, G. Zhang, H. Wu, B. Hai, L.Wang, Y. Qian, Nanoscale magnesium hydroxide and magnesium oxide powders-control over size, shape, and structure via hydrothermal synthesis, Chem. Mater. 13 (2001) 435-440. 
[12] W. Wang, X. Qiao, J. Chen, H. Li, Facile synthesis of magnesium oxide nanoplates via chemical precipitation, Mater. Lett. 61 (2007) 3218-3220.

[13] A. Samodi, A. Rashidi, K. Marjani, S. Ketabi, Effects of surfactants, solvents and time on the morphology of $\mathrm{MgO}$ nanoparticles prepared by the wet chemical method, Mater. Lett. 109 (2013) 269-274.

[14] A. Pilarska, E. Markiewicz, F. Ciesielczyk, T. Jesionowski, The influence of spray drying on the dispersive and physicochemical properties of magnesium oxide, Drying Technol. 29 (2011) 1210-1218.

[15] A.V.G. Chizmeshya, M.J. McKelvy, R. Sharma, R.W. Carpenter, H. Bearat, Density functional theory study of the decomposition of $\mathrm{Mg}(\mathrm{OH})_{2}$-a lamellar dehydroxylation model, Mater. Chem. Phys. 77 (2003) 416-425.

[16] P.J. Anderson, R.F. Horlqck, Thermal decomposition of magnesium hydroxide, Trans. Faraday Soc. 58 (1962) 1993-2004.

[17] J.F. Goodman, The decomposition of magnesium hydroxide in an electronic microscope, Proc. Roy. Soc. A 247 (1958) 346-352.

[18] H. Yoshioka, K. Amita, G. Hashizume, The nucleation-two dimensional interface growth equation for the thermal decomposition of $\mathrm{Mg}(\mathrm{OH})_{2}$, Netsu Sokutei 11 (1984) 115-118.

[19] M.J. McKelvy, R. Sharma, A.V.G. Chizmeshya, K. Streib, Magnesium hydroxide dehydroxylation: in situ nanoscale observations of lamellar nucleation and growth, Chem. Mater. 13 (2001) 921-926.

[20] D.D. Wang, Z.Q. Chen, C.Y. Li, X.F. Li, C.Y. Cao, Z. Tang, Correlation between ferromagnetism and defects in $\mathrm{MgO}$ nanocrystals studied by positron annihilation, Physica B 407 (2012) 2665-2669.

[21] Y.C. Jean, P.E. Mellon, D.M. Schrader, Principles and applications of positron and positronium chemistry, World Scientific, Singapore, 2003.

[22] V.P. Shantarovich, T. Suzuki, C. He, V.A. Davankov, A.V. Pastukhov, M.P. Tsyurupa, K. Kondo, Y. Ito, Positron annihilation study of hyper-cross-linked polystyrene networks, Macromolecules 35 (2002) 9723-9729.

[23] M.J. Puska, Theoretical aspects of positrons in imperfect solids, phys. stat. sol. (a) 102 (1987) 11-29.

[24] M.J. Puska, R.M. Nieminen, Defect spectroscopy with positrons-a general calculational method, J. Phys. F: Met. Phys. 13 (1983) 333-346. 
[25] X.D. Xue, L.L. Liu, Z. Wang, Y.C. Wu, Room-temperature ferromagnetism in hydrogenated ZnO nanoparticles, J. Appl. Phys. 115 (2014) 033902.

[26] X. Jiang, Y. Zhang, J. Jiang, Y. Rong, Y. Wang, Y. Wu, C. Pan, Characterization of oxygen vacancy associates within hydrogenated $\mathrm{TiO}_{2}$ : a positron annihilation study, J. Phys. Chem. C, 116 (2012) 22619-22624.

[27] P. Parente, Y. Ortega, B. Savoini, M.A. Monge, A. Tucci, L. Esposito, B. Ferrari, A.J. Sanchez-Herencia, Characterization of residual compressive stresses in layered ceramics by positron annihilation spectroscopy, J. Eur. Ceram. Soc. 32 (2012) 3989-3993.

[28] J. Engbrecht, D. Green, M.A. Hillmyer, D. Olson, E.M. Todd, Positron lifetime spectroscopy in ordered nanoporous polymers, J. Polym. Sci., Part B: Polym. Phys. 51 (2013) 1157-1161.

[29] S. Dutta, S. Chattopadhyay, D. Jana, A. Banerjee, S. Manik, S.K. Pradhan, M. Sutradhar, A. Sarkar, Annealing effect on nano-ZnO powder studied from positron lifetime and optical absorption spectroscopy, J. Appl. Phys. 100 (2006) 114328.

[30] J. Kansy, Microcomputer program for analysis of positron annihilation lifetime spectra, Nucl. Instrum, Methods Phys. Res., Sect. A 374 (1996) 235-244.

[31] D. Jin, X. Gu, X. Yu, G. Ding, H. Zhu, K. Yao, Hydrothermal synthesis and characterization of hexagonal $\mathrm{Mg}(\mathrm{OH})_{2}$ nano-flake as a flame retardant, Mater. Chem. Phys. 112 (2008) 962-965.

[32] V. Ciupină, S. Zamfirescu, G. Prodan, Evaluation of mean diameter values using Scherrer equation applied to electron diffraction images, Nanotechnology-Toxicologica Issues and Environmental Safety and Environmental Safety, Springer Netherlands, 2007, pp. 231-237.

[33] T. Yoshida, T. Tanaka, H. Yoshida, T. Funabiki, S. Yoshida, Study of dehydration of magnesium hydroxide, J. Phys. Chem. 99 (1995) 10890-10896.

[34] M.G. Kim, U. Dahmen, A.W. Searcy, Structural transformations in the decomposition of $\mathrm{Mg}(\mathrm{OH})_{2}$ and $\mathrm{MgCO}_{3}$, J. Am. Ceram. Soc. 70 (1987) 146-154.

[35] X. Ma, H. Ma, X. Jiang, Z. Jiang, Preparation of magnesium hydroxide nanoflowers from boron mud via anti-drop precipitation method, Mater. Res. Bull. 56 (2014) 113-118.

[36] S. Lan, L. Li, D. Xu, D. Zhu, Z. Liu, F. Nie, Surface modification of magnesium hydroxide using vinyltriethoxysilane by dry process, Appl. Surf. Sci. 382 (2016) $56-62$. 
[37] M.J. Puska, Positron Annihilation, World Scientific, New Jersey, 2008.

[38] C. Bussolati, A. Dupasquier, L. Zappa, Positron bound states in alkali halides, II Nuovo Cimento B 52 (1967) 529-538.

[39] K.P. Singh, R.M. Singru, Positron lifetimes in some ionic compounds, Phys. Lett. А 33 (1970) 463-464.

[40] A. Sundaresan, R. Bhargavi, N. Rangarajan, U. Siddesh, C.N.R. Rao, Ferromagnetism as a universal feature of nanoparticles of the otherwise nonmagnetic oxides, Phys. Lett. B 74 (2006) 161306.

[41] S. Phokha, J. Klinkaewnarong, S. Hunpratub, K. Boonserm, E. Swatsitang, S. Maensiri, Ferromagnetism in Fe-doped MgO nanoparticles, J. Mater. Sci. - Mater. Electron. 27 (2015) 33-39.

[42] H.E. Schaefer, R. Würschum, R. Birringer, H. Gleiter, Structure of nanometer-sized polycrystalline iron investigated by positron lifetime spectroscopy, Phys. Rev. B 38 (1988) 9545-9554. 


\section{Figure captions:}

Fig. 1 XRD patterns of $\mathrm{Mg}(\mathrm{OH})_{2}$ nanopowders annealed in air at different temperatures.

Fig. 2 The average grain size calculated from full width at half maximum of the diffraction peaks by Scherrer equation as a function of annealing temperatures.

Fig. $3 \mathrm{TG}$ and DSC curves of $\mathrm{Mg}(\mathrm{OH})_{2}$ nanopowders in the temperature range of $25 \sim 800{ }^{\circ} \mathrm{C}$ with a heating rate of $5^{\circ} \mathrm{C} / \mathrm{min}$.

Fig. 4 The original positron lifetime spectra of $\operatorname{Mg}(\mathrm{OH})_{2}$ annealing samples, with fitting lines of as-recieved sample (blue) and $400{ }^{\circ} \mathrm{C}$ annealed sample (red).

Fig. 5 The positron lifetimes (a) $\tau_{1}$, (b) $\tau_{2}$, (c) $\tau_{3}$ and the corresponding relative intensities (d) $I_{1}$, (e) $I_{2}$, (f) $I_{3}$ of $\operatorname{Mg}(O H)_{2}$ nanopowders as a function of annealing temperature.

Fig. 6 Schematic of positron trapping model for the thermal decomposition from $\mathrm{Mg}(\mathrm{OH})_{2}$ nanoparticles to $\mathrm{MgO}$. The hatching indicates the orientation of lattice planes. The various tapping sites are attributed to the positron lifetimes (1) $\tau_{1}$, interfacial vacancies/vacancy complexes at grain boundary areas, the atomic structure shown in the inset, (2) $\tau_{2}$, vacancy clusters at the intersections of several interfaces, (3) $\tau_{3}$, open and closed microvoids in particles.

Fig. 7 Low-magnification TEM images of $\mathrm{Mg}(\mathrm{OH})_{2}$ nanoparticles (a) the as-received sample and (b) the $400{ }^{\circ} \mathrm{C}$ annealed sample.

Fig. 8 (a) High-magnification TEM (HRTEM) image of $\mathrm{Mg}(\mathrm{OH})_{2}$ nanoparticles annealed at $400{ }^{\circ} \mathrm{C}$ and (b) Magnified HRTEM image with lattice fringes separated by $0.243 \mathrm{~nm}$ corresponding to the (111) plane of $\mathrm{MgO}$.

Fig. 9 SEM images of $\mathrm{Mg}(\mathrm{OH})_{2}$ nanopowders annealed at different temperatures, (a) as-received, (b) $350{ }^{\circ} \mathrm{C}$, (c) $400{ }^{\circ} \mathrm{C}$. 
Figures:

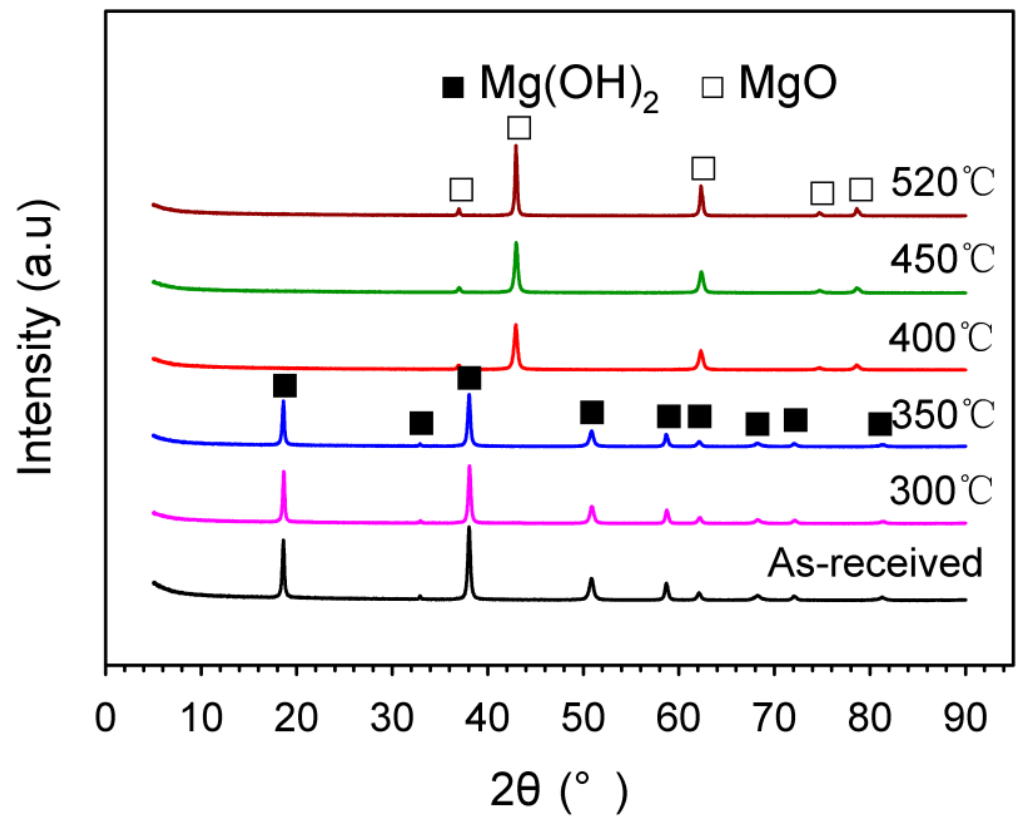

Figure. 1

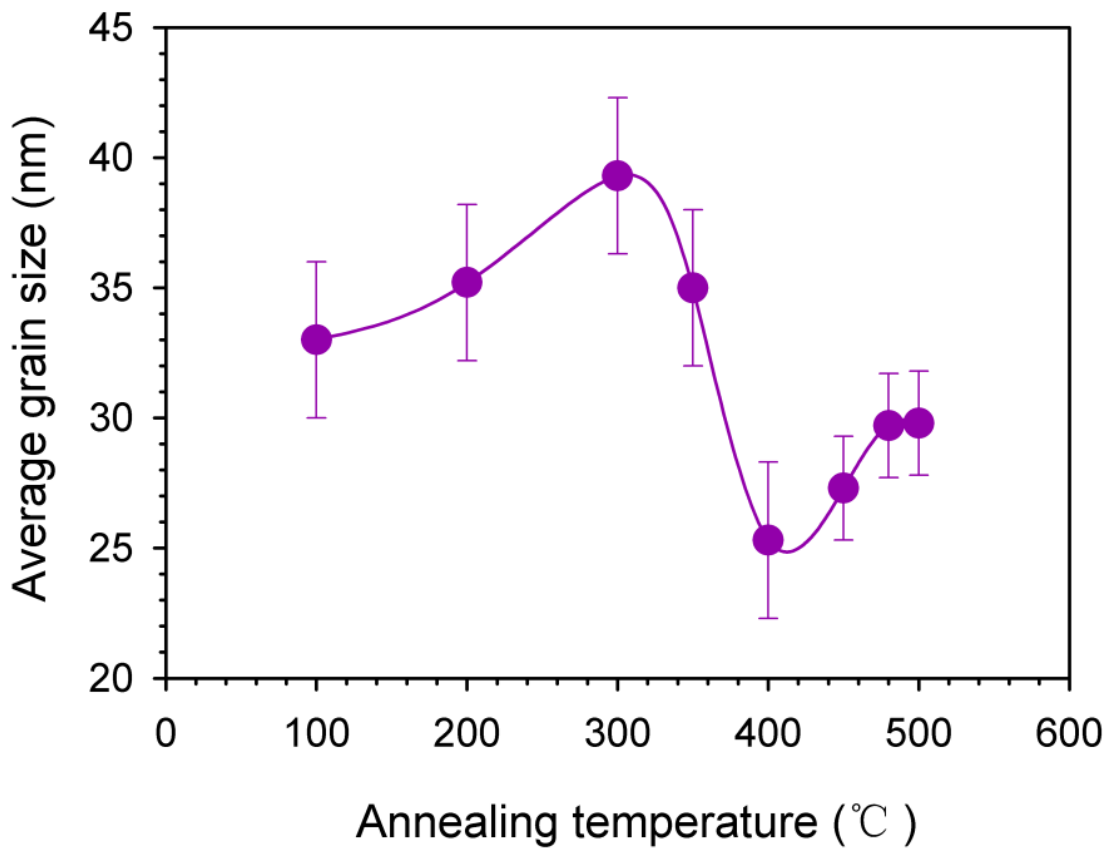

Figure. 2 


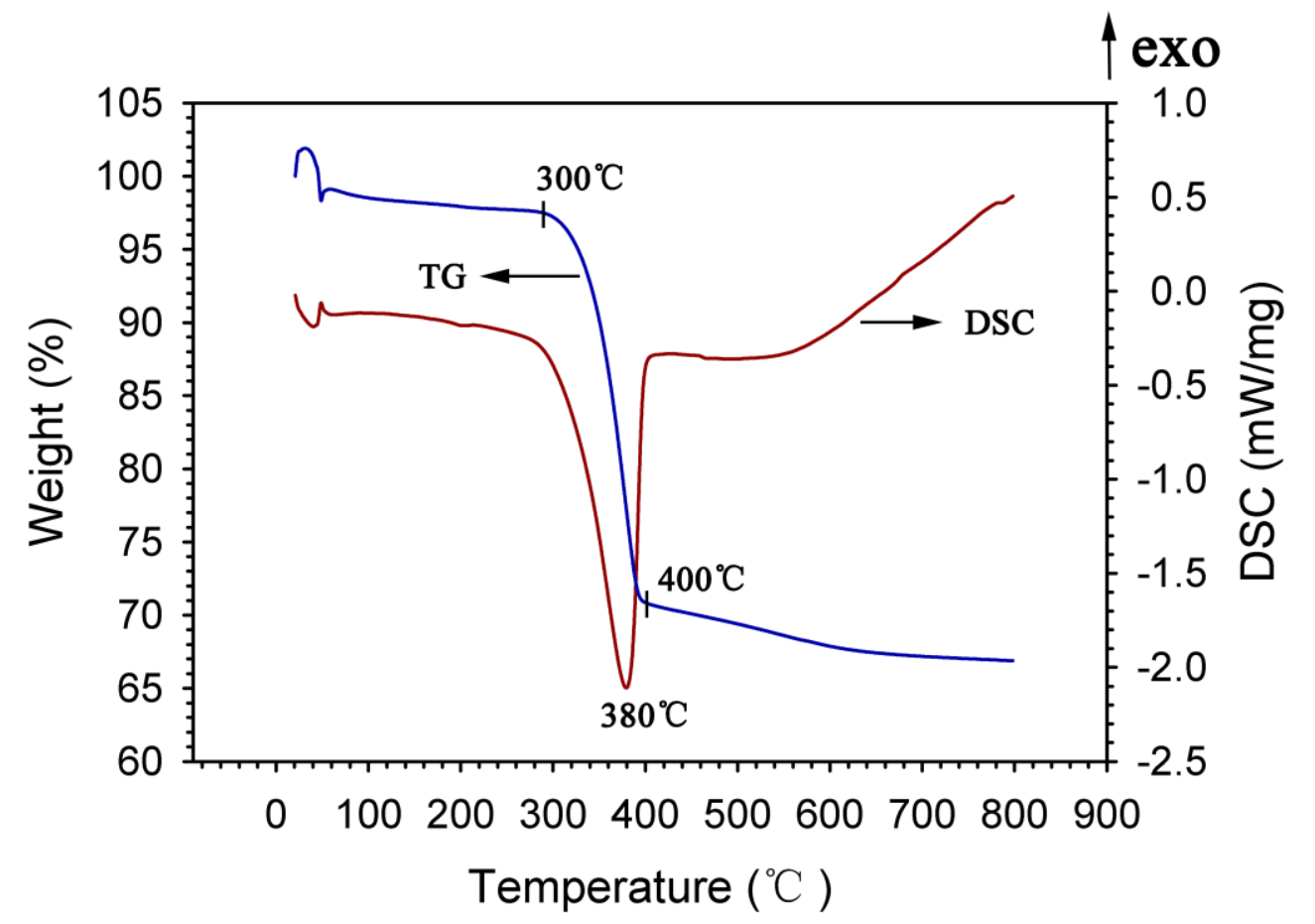

Figure. 3

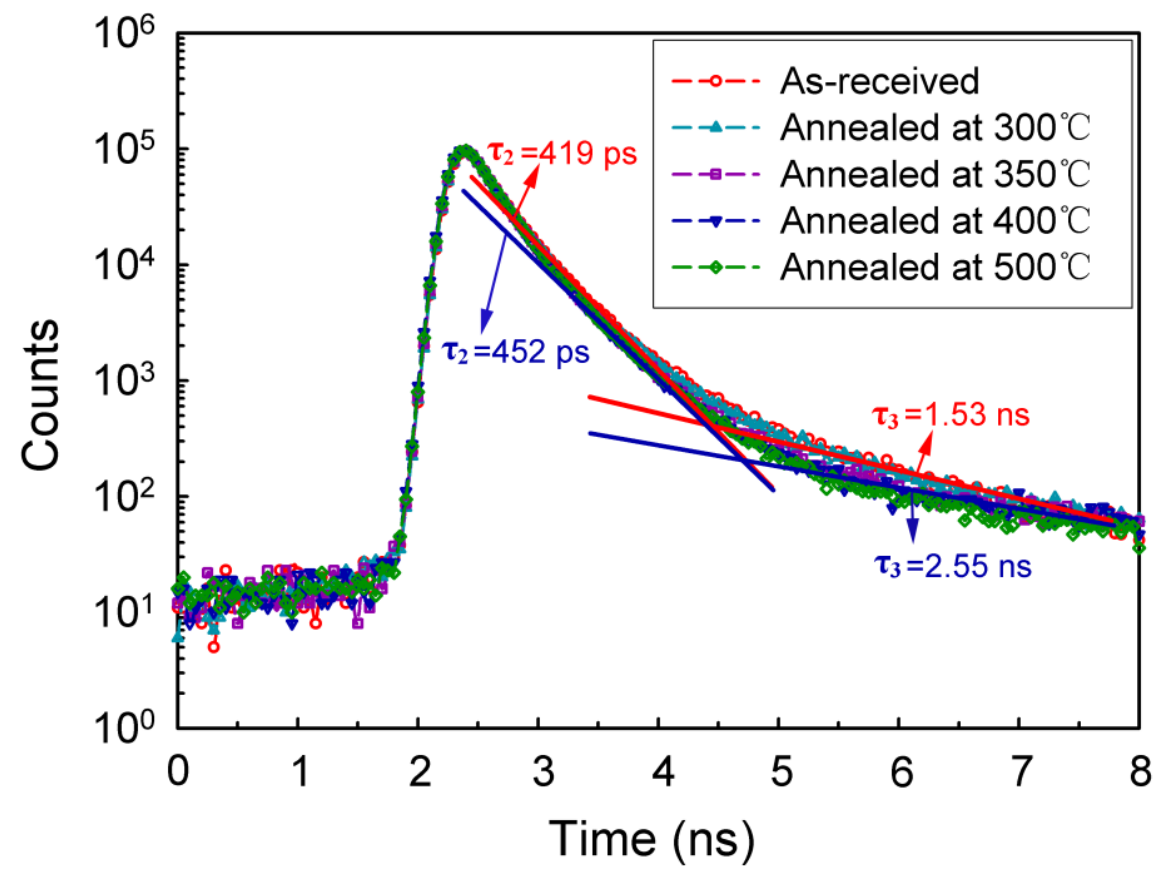

Figure. 4 

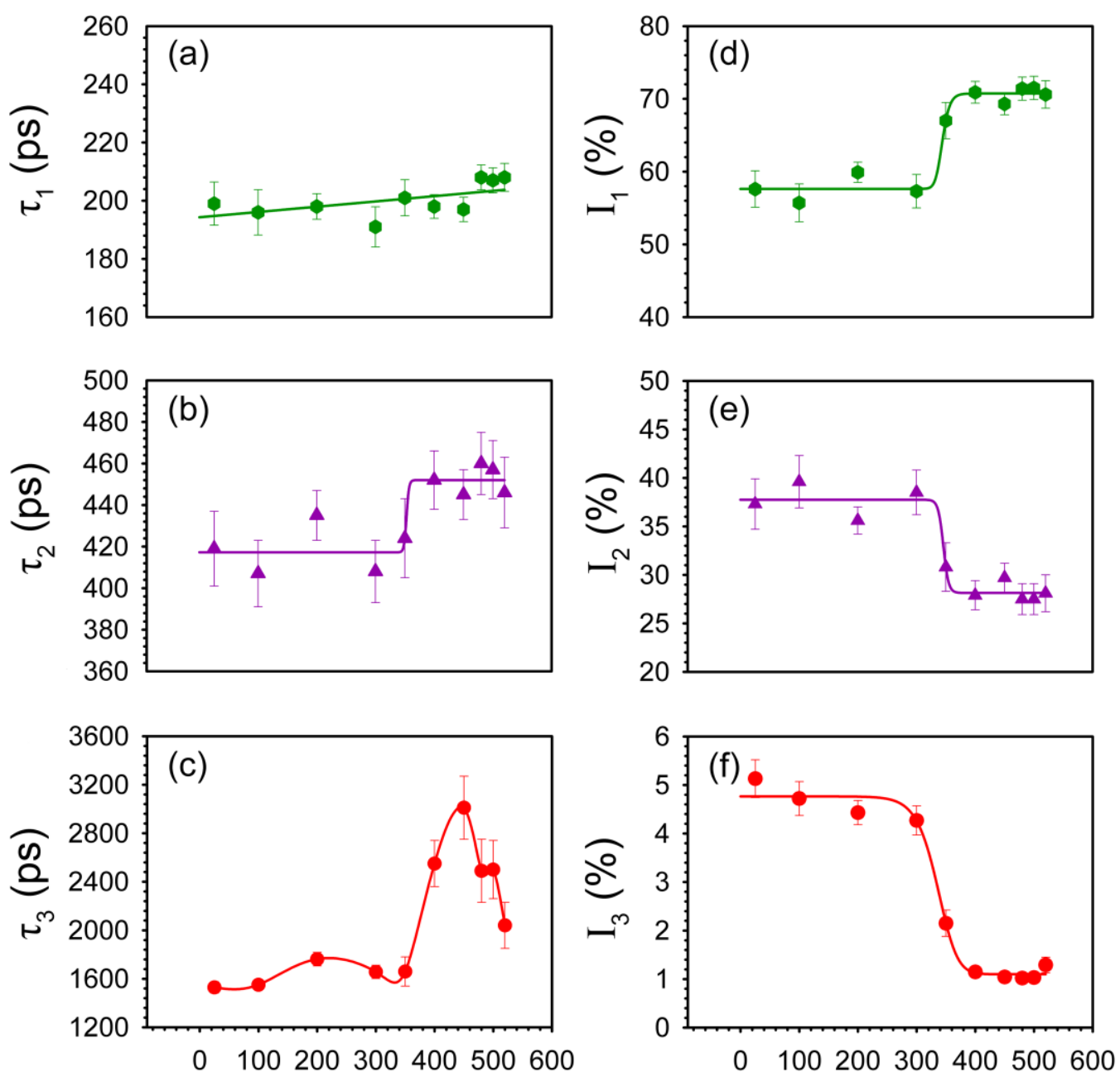

Annealing temperature $\left({ }^{\circ} \mathrm{C}\right)$ Annealing temperature $\left({ }^{\circ} \mathrm{C}\right)$

Figure. 5 
$\mathrm{Mg}(\mathrm{OH})_{2}$ nanoparticle

(2)

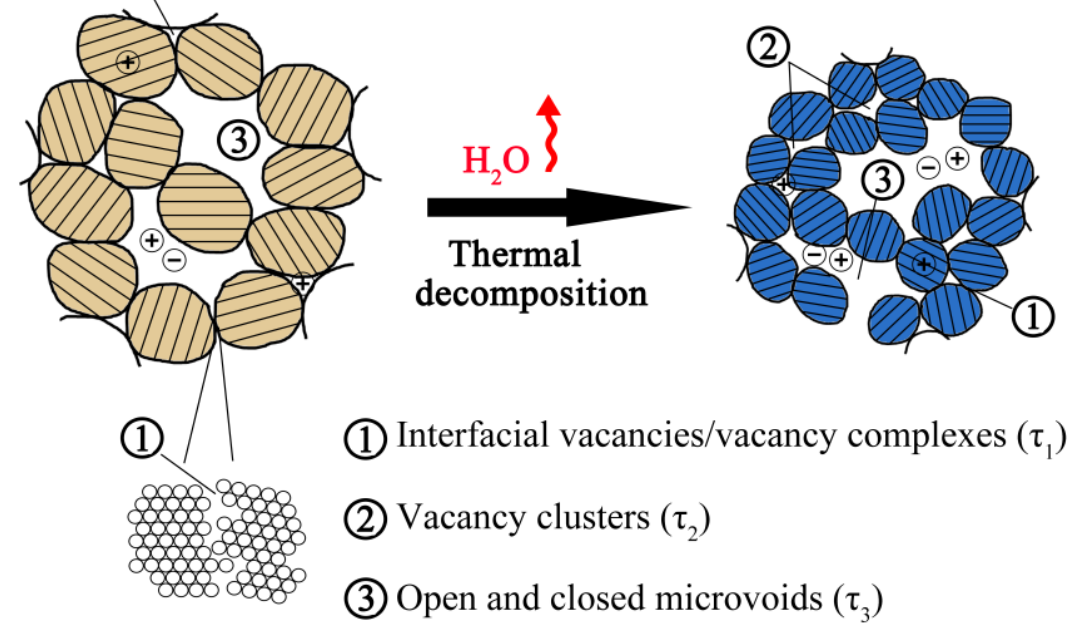

Figure. 6
$\mathrm{MgO}$ product particle
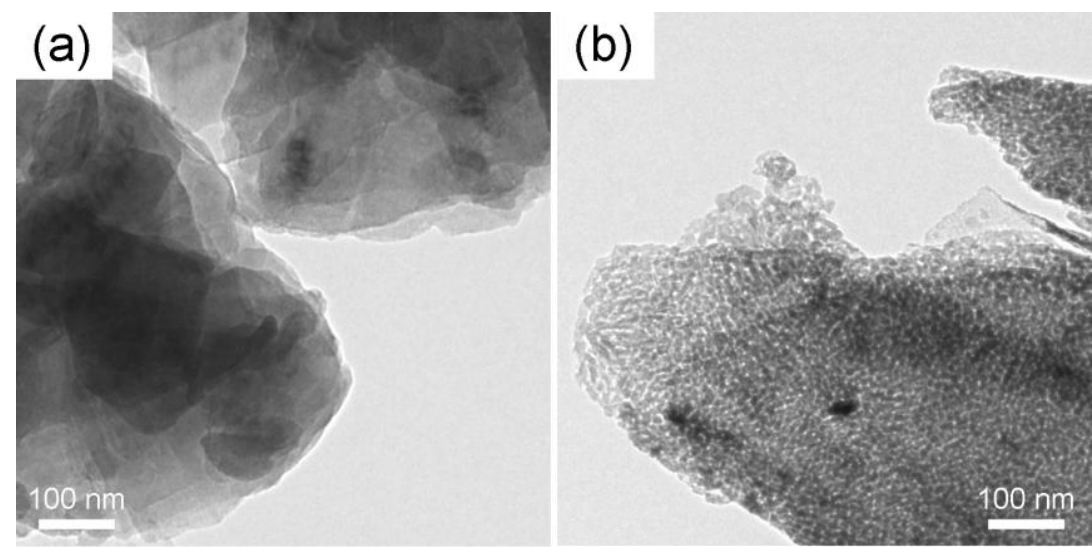

Figure. 7 


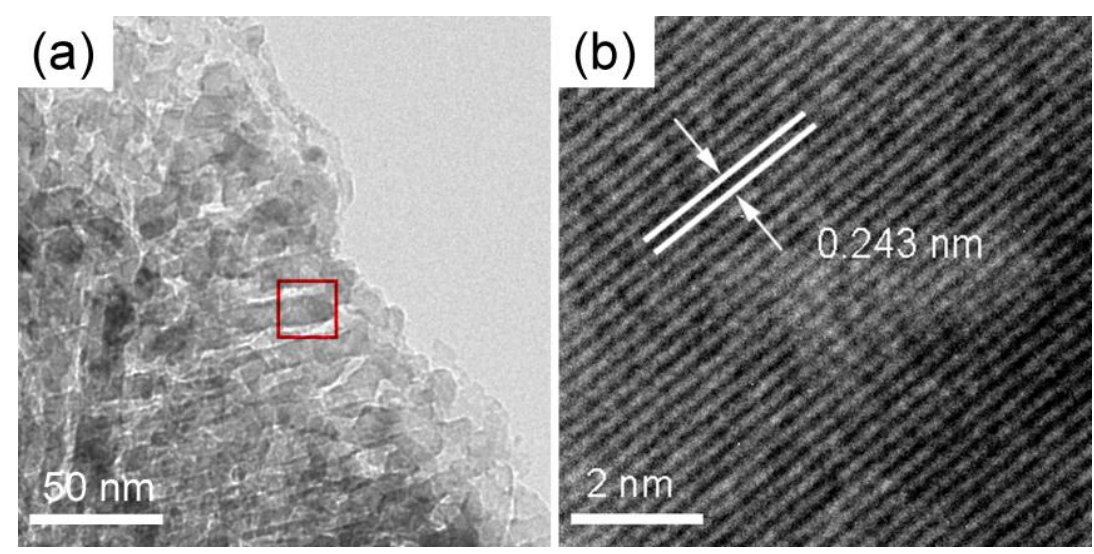

Figure. 8
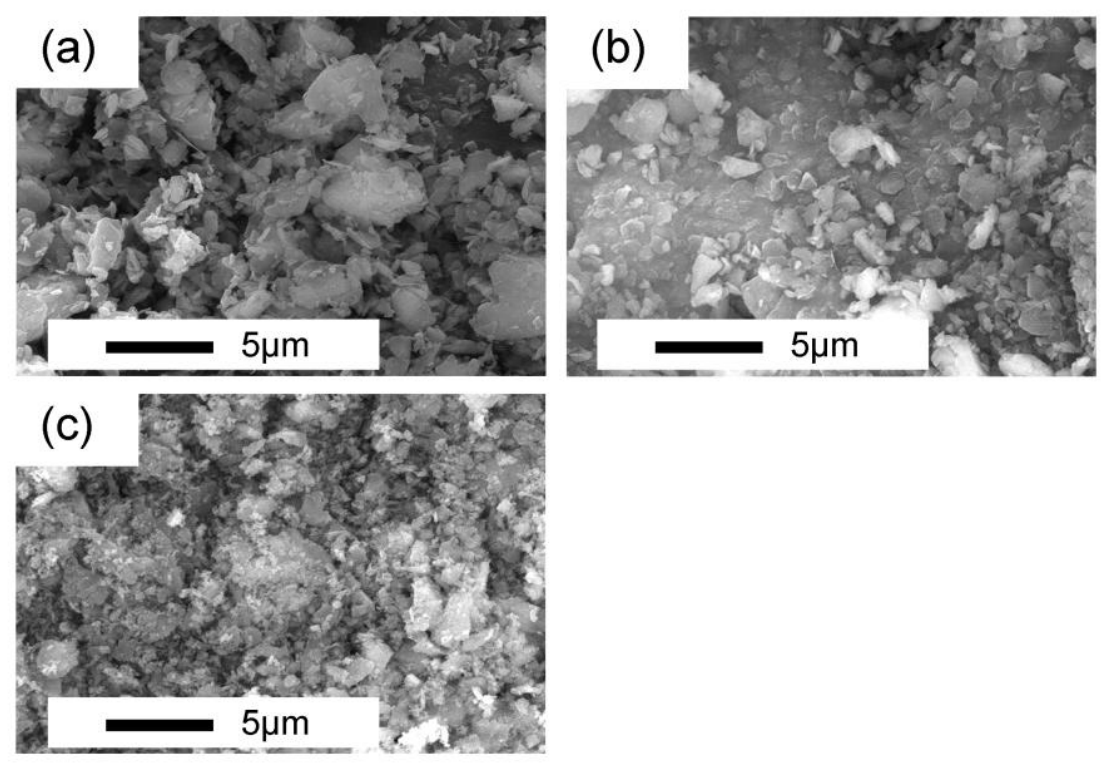

Figure. 9 
Tables:

Table 1 The experimental lifetime $\tau_{1}$ (ps) of as-received $\mathrm{Mg}(\mathrm{OH})_{2}$ nanoparticles and decomposition product $\mathrm{MgO}$ annealed at $520{ }^{\circ} \mathrm{C}$, and calculated lifetimes (ps) of perfect $\mathrm{Mg}(\mathrm{OH})_{2}$ and $\mathrm{MgO}$ lattices with and without vacancy defect.

\begin{tabular}{lccccc}
\hline Sample & $\begin{array}{l}\text { Experimental } \\
\text { lifetime } \tau_{1}(\mathrm{ps})\end{array}$ & \multicolumn{2}{l}{$\begin{array}{l}\text { Theoretical lifetimes } \\
\text { vacancy defect }\end{array}$} & $\tau_{1}$ (ps) with and without \\
\cline { 3 - 6 } & & bulk & $V_{\mathrm{Mg}}$ & $V_{\mathrm{OH}}$ & $V_{\mathrm{Mg}-\mathrm{OH}}$ \\
\hline $\mathrm{Mg}(\mathrm{OH})_{2}$ & $199 \pm 7.8$ & 176 & 184 & 189 & 215 \\
$\mathrm{MgO}$ & $208 \pm 4.8$ & 123 & 174 & $/$ & $/$ \\
\hline
\end{tabular}




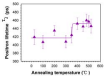

Shoctio mageticin

di
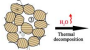

(1)

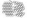

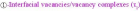
Q-Varzery clusters (7)

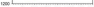

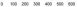
Awexing xepermen (C)

\section{Sy0 podact paride}

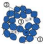

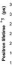

